\title{
ANÁLISES DE DIREITO COMPARADO SOBRE SEGURANÇA, CRIMINALIDADE E POLÍTICAS PÚBLICAS - PANORAMA BRASIL E ITÁLIA
}

\author{
Carolina Mota de Freitas* \\ Janaína Taddeu Calil de Freitas ${ }^{* *}$
}

\begin{abstract}
RESUMO
A criminalidade global vem avançando em níveis assustadores nas últimas décadas, o que acaba por ocasionar grande preocupação não só da população como dos governantes em todos os níveis. Com uma análise específica das atuais políticas públicas brasleiras, percebe-se que pouco é feito na direção da diminuição de tais índices. A sociedade assiste atônita à infinidade de crimes que ocorrem diariamente, sem se dar conta da responsabilidade que também possui diante dos fatos. Tendo em vista tais fatores, o presente estudo pretende analisar a criminalidade sob o enfoque da realidade mundial, mediante exposição e análise das experiências de direito comparado, principalmente no contexto brasileiro e italiano, de modo a propor políticas públicas relativas à prevenção do crime, visando assim a contenção ou diminuição dos coeficientes de criminalidade alarmantes.
\end{abstract}

PALAVRAS-CHAVE: Criminalidade. Políticas públicas e segurança.

\begin{abstract}
Global crime comes in scary levels advancing in recent decades, which ultimately cause not only great concern of the population as of the rulers in all levels. With a specific analysis of current Brazilian public policies, not much has been done towards the reduction of such indexes. The Society assists astonished the myriad of crimes that occur daily, without realizing its own responsibility. In view of these factors, the present study aims to analyze the crime under the focus of world reality, through exposure and analysis of comparative
\end{abstract}

Advogada. Mestranda do Programa de Pós-Graduação em Direito e Justiça Social pela Universidade Federal do Rio Grande - FURG.

Advogada. Doutorado em Sistemi punitivi e Garanzie Costituzionali pela Scuola Dottorale Internazionale "Tullio Ascarelliee da Università degli Studi Roma 3 
law experiences, especially in the Brazilian and Italian context, in order to propose public policies on the prevention of crime, in order to contain or decrease the alarming crime rate coefficients.

KEY-WORDS: Crime. Public policy and security.

\section{INTRODUÇÃO}

O presente artigo apresentará uma reflexão acerca do problema ainda muito vivenciado quanto ao combate à criminalidade facilmente demonstrado pelos altos níveis obtidos ao redor do mundo. Diante desta situação, impõe-se o questionamento quanto à força e à eficiência das políticas públicas de segurança uma vez que nitidamente não estão alcançando o objetivo primordial de segurança da sociedade.

Tendo esta conjuntura em conta, o estudo partirá de uma breve análise dos índices e das pesquisas existentes sobre a realidade brasileira, em especial, a fim de delimitar a situação atual acerca da criminalidade e da violência no país. Para tanto, será necessária uma pequena incursão nas possíveis causas já conhecidas deste problema social como pobreza, desigualdade social, a facilidade de acesso às armas de fogo e o consumo disseminado de drogas em todos os extratos sociais. Além disto, outras determinantes serão expostas e dissecadas a fim de corroborar com a tentativa de solucionar a indagação proposta inicialmente traçando como paradigma as experiências e análises encontradas no Direito comparado, notadamente, no contexto italiano.

Inseridas na realidade fática brasileira, serão analisadas também as políticas públicas existentes em matéria de segurança pública a fim de que seja averiguado de que forma o problema vem sendo enfrentado pelo poder público, e até mesmo pela sociedade, para que então seja possível começarmos a delinear alguns caminhos que apontem para a redução da criminalidade. Neste aspecto, será analisada a importância das políticas públicas preventivas, ainda que algumas delas demonstrem resultados a longo prazo, bem como o revés das políticas públicas repressivas.

Não obstante, a prioridade de atuação no âmbito social deverá ser posta em prática a fim de que obtenhamos efeitos também na 
esfera penal-penitenciária. De antemão, já se percebe indiscutível a necessidade de investimento em direitos sociais mediante combinação de medidas capazes de afrontar o problema nos seus mais variados aspectos, principalmente através da adoção de medidas externas ao direito penal.

A exemplo da realidade italiana, RUOTOLO (2011) demarca com precisão sua análise sobre como a prisão não deveria ser e afirma que existe muita resistência dos governos em reconhecer e respeitar a dignidade dos apenados, de colocá-los no mesmo patamar da dignidade dos sujeitos livres. Sustenta que a pena deve limitar somente a liberdade de ir e vir, sem que ocorra a restrição dos demais direitos garantidos pela Constituição. Todavia, e infelizmente, é normal que, em dado contexto de falta de recursos e superpopulação carcerária, tais direitos dificilmente sejam respeitados. Deste modo, para obter-se o resultado desejado é importante adotarmos uma série de medidas que valorizem e respeitem os direitos tutelados pela Constituição, seja dentro ou fora da prisão.

Além disto, RUOTOLO (2011) afirma que, cada vez mais, os governos têm privilegiado o direito a segurança em detrimento da segurança do direito (expressão utilizada por Alessandro Baratta), pois os Estados colocam como prioridade a manutenção da ordem pública, deixando em segundo plano o respeito à segurança social. Tal inversão de valores pode ser evidenciada através da implementação de uma serie de políticas que "vanno in un senso contrario all'obiettivo dell'inclusione sociale" e da suspensão de programas capazes de desenvolver e estimular a inclusão social (cotas nas universidades, bolsa família, entre outros exemplos acerca dos programas sociais brasileiros). ${ }^{1}$

Assim, depois de observados e cotejados todos estes passos, o resultado será a apresentação do que entendemos ser o primeiro passo em direção à possível saída para o dilema da criminalidade de forma que se amolde às manifestações, nos mais diversos setores da sociedade, proporcionando, ao final, segurança e bem-estar a todos.

\footnotetext{
${ }^{1}$ Para aprofundar a temática acerca da realidade italiana sugerimos: RUOTOLO, 2012, p. 15 em diante e BARATTA, 2001, p. 19 e ss.
} 


\section{ANÁLISE SOBRE A REALIDADE: AS CONDICIONANTES DA CRIMINALIDADE E A CRESCENTE VIOLÊNCIA MUNDIAL}

Inúmeras notícias são divulgadas nos mais diversos meios de comunicação (televisão, jornais, sites, blogs, etc), diariamente, dando conta do espantoso aumento da criminalidade mundo a fora. Tem se tornado quase impossível, nos dias atuais, que uma família razoavelmente numerosa não tenha pelo menos um membro envolvido em dada situação de risco. A sensação de insegurança das populações é algo presente e que cresce assustadoramente, acompanhando, assim, os níveis de violência.

Muitas são as causas apontadas para a origem e crescimento da violência em sociedade, entre elas encontramos as famigeradas: condição de pobreza e miserabilidade de maior parte da população que derivam de outra causa, a desigualdade social provocada pela globalização, bem como o acesso e o uso de armas de fogo e o grave problema do consumo cada vez mais intenso de todo tipo de drogas.

A evolução social decorrente dos processos de globalização tem trazido uma série de decorrências positivas para o avanço da humanidade, é inegável, sobretudo no que toca à introdução de novas tecnologias. Todavia, no campo social as consequiências têm se mostrado ruins, senão catastróficas, principalmente no que diz respeito à (des)igualdade. Aliada à extrema pobreza e às condições de verdadeira miserabilidade, o contingente de marginalizados sociais só aumenta. O contexto dito "à margem" envolve, com intensidades diferentes, desde moradia em condições subumanas (sem mencionar os casos de mendicância e os moradores de rua) até a falta de saneamento básico, educação, saúde e alimentação.

$\mathrm{O}$ arquétipo de sociedade desigual infligido pela globalização desvaloriza o ser humano e acaba por impor uma acirrada competitividade no mercado de trabalho, concentrando renda nas mãos de poucos, retroalimentando mais e maiores desigualdades sociais. Este panorama de miserabilidade social acaba propiciando a inserção no chamado "mundo do crime" já que o cidadão não se vê inserido no contexto social e busca, através da criminalidade, uma renda rápida para alcançar seus demais anseios de alimentação, moradia, bens de consumo e até drogas. 
Especialista no assunto, o brasileiro Luiz Eduardo Soares vai além e taxativamente afirma que:

Em outras palavras, pobreza e desigualdade são e não são condicionantes da criminalidade, dependendo do tipo de crime, do contexto intersubjetivo e do horizonte cultural a que nos referirmos. Esse quadro complexo exige políticas sensíveis às várias dimensões que o compõem. É tempo de aposentar as visões unilaterais e o voluntarismo (SOARES, 2006, p. 94).

Em que pese tal situação de extrema pobreza, e se analisarmos especificamente a realidade brasileira na última década, perceberemos que milhões de pessoas foram retiradas da condição de extrema pobreza e miserabilidade mediante programas assistenciais e de transferência de renda. ${ }^{2}$ Por si só, este aspecto conduziria a outro estudo pormenorizado quanto à aplicabilidade de tais propostas estatais, bem como sobre a necessidade de fiscalização destes para bem do benefício oferecido. $\mathrm{O}$ que se pretende aqui, contudo, tem foco diverso, portanto, seguimos adiante.

Segundo a análise de José Vicente da Silva Filho, a sociedade também possui sua parcela de culpa no que diz respeito à violência: $a$ sociedade tolera a desordem, incentiva comportamentos desviantes e soluções agressivas aos corriqueiros conflitos humanos, além de consumir produtos de entretenimento que exploram a degradação do caráter humano. (FILHO, 1998, p. 07).

Especificamente analisando a realidade brasileira, no que tange aos índices de criminalidade e violência nacional, muitas são as pesquisas desenvolvidas, contudo apenas para fins de fixação de um parâmetro e delimitação da pesquisa ora apresentada, não serão informadas todas as análises existentes, mas apenas aquelas consideradas peças-chave para o entendimento e exame das atuais políticas públicas de segurança nacionais.

${ }^{2}$ Segundo o Ministério do Desenvolvimento Social e Combate à Fome (MDS), o programa já tirou 36 milhões de pessoas da situação de extrema pobreza. Disponível em: http://www.brasil.gov.br/cidadania-e-justica/2013/09/em-10-anos-bolsa-familiatirou-36-milhoes-pessoas-da-extrema-pobreza Acesso em 19/04/2017. 
O atlas da violência ${ }^{3}$ de 2016, desenvolvido pelo IPEA, demonstra que os índices de violência aumentaram ao longo dos anos. Em especial no ano de 2014, a taxa de homicídios cresceu em razão da difusão das armas de fogo e relativamente às políticas públicas aplicadas, tal estudo atribui ao Estatuto do Desarmamento fator importante de contenção deste crescimento. A nota técnica desenvolvida ainda dá conta de que o número de homicídios contra mulheres, jovens e afrodescendentes cresceu vertiginosamente nos últimos anos.

Por sua vez, o IPS - índice de progresso social ${ }^{4}$ - de 2014 apontou a violência como o fator central impeditivo do desenvolvimento social do Brasil, fazendo com que caia o desempenho relativamente à qualidade de vida. A partir de tal pesquisa, o país ocupa atualmente (IPS 2015) a $46^{\mathrm{a}}$ posição quanto ao índice de progresso social e a $74^{a}$ posição no ranking global relativamente às necessidades humanas básicas (nestes incluídos itens como cuidados médicos básicos, moradia e segurança pessoal).

Tal análise é ainda mais estarrecedora no tocante à segurança pessoal visto que o Brasil alcança o $122^{\circ}$ lugar na lista dos 132 países pesquisados, o que demonstra ser um dos países menos seguros para se viver. Em tal exame são levados em conta cinco quesitos para avaliar o nível de segurança dos cidadãos: taxa de homicídios, nível de crimes violentos, percepção sobre a criminalidade, terror político e mortes no trânsito.

E ainda, ressalta-se que o somatório do país é de 37,25 pontos no quesito "segurança pessoal", e considerando uma escala de 0 a 100,

\footnotetext{
${ }^{3}$ A nota técnica ${ }^{\circ}$ 17, traz o Atlas da violência de 2016 desenvolvido pelo IPEA instituto de pesquisa econômica aplicada, Fundação pública vinculada ao Ministério do Planejamento, Orçamento e Gestão. Disponível em: http://www.ipea.gov.br/portal/images/stories/PDFs/nota_tecnica/160322_nt_17_atla s_da_violencia_2016_finalizado.pdf acesso em 12/04/2017.

${ }^{4}$ A organização sem fins lucrativos, denominada SPI - Social Progress Imperative, fundada em 2012 nos Estados Unidos da América, propõe a verificação do crescimento de uma nação independente do desenvolvimento econômico. Inicialmente a pesquisa tinha caráter global, mas progressivamente foi expandindo para Estados, municípios e regiões determinadas. Atualmente no Brasil, existe a Rede Progresso Social Brasil que visa criar processos colaborativos em rede com parceiros no governo, empresas e sociedade civil. http://www.progressosocial.org.br/
} 
evidencia-se pontuação muito baixa. Além disso, no que diz respeito à percepção geral sobre a criminalidade, o país ficou classificado no nível 4, (escala de 1 a 5 , onde 5 representa a menor confiança possível da maioria dos cidadãos).

Estes dados estatísticos, ainda que não retratem a totalidade das regiões do Brasil e ainda que existam diversos outros estudos e pesquisas acerca da violência não mencionados aqui, demonstram com clareza o crescimento da criminalidade nacional. Diante destes resultados, indagamos: Por onde andam as políticas públicas de segurança? Qual o nível de eficácia das políticas atualmente existentes? Não seria necessária a formulação de novas e diferentes políticas públicas de segurança? Aqui reside boa parte do problema que será enfrentando no tópico de análise seguinte utilizando-se dos estudos e experiências estrangeiras, notadamente a realidade italiana.

Para além da realidade quanto ao aumento significativo da criminalidade envolvendo tais motivações, é importante ressaltar o papel da mídia de massa que acaba por contribuir com o aumento da sensação de insegurança social já que nitidamente deturpa a realidade sobre os fatos ocorridos. Diversos são os estudos, no âmbito da criminologia e da sociologia, que bem demonstram a parcela de responsabilidade pelo terror noticiado via imprensa.

A análise do papel da chamada mass media aliada ao fenômeno da segurança não é algo novo já que remonta aos primeiros estudos realizados pelas famosas escolas de Chicago (Estados Unidos, décadas de 1940 e 1950) e de Frankfurt. Em especial, importante ressaltar a teoria crítica prenunciada pelos pensadores europeus alemães que se debruçaram à estudar as relações existentes entre crítica, sociedade e cultura.

Os pesquisadores da Escola de Frankfurt caracterizaram um sistema que transforma progresso cultural no seu contrário a partir principalmente do cinema, da televisão, do rádio e dos jornais submetidos a um mercado de massas que impõe estandartização de baixa qualidade, moldando os gostos do público e suas necessidades. Esse sistema condicionaria de forma total o processo de consumo e sua qualidade, bem como a autonomia do consumidor. (RAMOS, 2014, p. 177).

Para demonstrar tal fenômeno, é interessante observar o modo como a mídia europeia e italiana se manifesta em relação à questão 
dos atentados terroristas promovidos pelo Estado Islâmico. Os jornais, veiculando informações de modo perverso e irresponsável, muitas vezes associam os atentados à questão da emergência migratória ignorando que, em muitos dos diversos atentandos ocorridos recentemente na Europa, os terroristas eram cidadãos de um Estado da União europeia por iure soli, nascidos em território europeu. Além disso, e para agravar o quadro da situação, muitas vezes ocorre uma associação de modo indistinto, entre religião islâmica e terrorismo. Algo como se todos os musulmanos fossem terroristas ou potenciais terroristas. Tudo isto, além de criar um forte clima de tensão, favorece e estimula o desencadear de ódio, xenofobia, discriminação e intolerância, feitos que desencadeiam e alimentam a violência.

Este fenômeno não se verifica somente no contexto estadunidense ou europeu, haja vista que no Brasil não ocorre de modo diferente. A banalização de diversos assuntos e temas, entre elas a violência, tem sido objeto de análise e críticas em todas as esferas científicas. Indaga-se acerca do papel da mídia de massa vista como integrante de um sistema político livre e o que parece importante a ser fixado, e também para que não se alongue tal debate já que diverge da temática central de discussão aqui proposta, é a necessidade de limites éticos a esta atuação da imprensa.

Evidentemente que o estabelecimento de tais limites deve estar de acordo com a ordem legal vigente, principalmente quanto ao direito à informação e à liberdade de imprensa. Contudo torna-se imprescindível estabelecer certa disciplina relativamente às atividades da empresa jornalística por meio da fixação de responsabilidades quanto aos destinatários e até mesmo sobre os terceiros que por ventura possam ser atingidos pela divulgação.

Neste particular, importante mencionar a fala do sociólogo francês Pierre Bourdieu no diz respeito às divulgações visando movimentar as chamadas massas de manobra política através da violência simbólica. A influência desta mídia parcial e compromissada com interesses outros, diversos dos verdadeiros motivos da luta contra a criminalidade, propaga, fomenta e até mesmo estimula tudo aquilo que se pretende combater. 
As pessoas, de maneira geral, não gostam muito de ser tomadas como objetos, objetivadas, e os jornalistas ainda menos que as outras. Eles se sentem visados, alfinetados, quando, ao contrário, quanto mais se avança na análise de um meio, mais se é levado a isentar os indivíduos de sua responsabilidade - o que não quer dizer que se justifique tudo o que se passa ali - e quanto melhor se compreende como ele funciona, mais se compreende também que aqueles que dele participam são tão manipulados quanto manipuladores. Manipulam mesmo tanto melhor, bem frequentemente, quanto mais manipulados são eles próprios e mais inconscientes de sê-lo (BOURDIEU, 1997, p. 21).

A diversidade de determinantes da criminalidade mundial define a necessidade de enfrentamento multisetorial do problema, requer a participação ativa da sociedade civil e, sobretudo, uma atuação focada do poder público no sentido de atacar suas causas de forma a combatê-las de modo eficaz. Como isto vem ocorrendo na prática, eficientemente ou não, é o que se pretende analisar a seguir.

\section{CONSIDERAÇÕES SOBRE AS ATUAIS POLÍTICAS PÚBLICAS DE SEGURANÇA NO BRASIL EM COTEJO COM A REALIDADE ITALIANA}

Relativamente à sua origem, no Brasil, a necessidade de implementação de políticas públicas vem associada ao período que sobreveio a ditadura militar, década de 1970, momento em que nitidamente ascenderam os movimentos sociais e populares, até então reprimidos com o silêncio militar. O norte de tais movimentos era a luta pela democracia visando a extensão dos direitos básicos a todos os cidadãos, o que fez com que a preocupação com chamada questão social fosse pauta de grandes reivindicações.

Aos poucos foi evoluindo a formulação de um conceito e delimitação da questão social a ponto de tornar-se notadamente elemento chave na busca pelo bem-estar social na medida em que as políticas públicas foram definidas como um conjunto de ações coordenadas e atuantes em diversas áreas, de modo a influenciar a vida de todos os cidadãos. Percebe-se, com isto, a forte ligação que a questão possui com a perfectibilização da cidadania.

Especificamente quanto à segurança, as políticas públicas 
vigentes atualmente no Brasil ainda decorrem de uma lógica historicamente diversa da atualidade, isto é, percebe-se que nitidamente não acompanharam a evolução da sociedade tampouco a evolução assustadora da criminalidade. Como antes mencionado, os índices de criminalidade aumentam a cada ano, com incremento de novas modalidades criminosas, notadamente cada dia mais cruéis e violentamente perversas, ao passo que percebemos as mesmas estratégias governamentais de dez anos atrás (ou mais), demonstrando-se claramente ineficientes e ainda centralizadas exclusivamente na repressão.

Demonstra-se indissociável desta análise, perquirir rapidamente acerca da evolução social ditada pelo capitalismo que interfere e muito, senão totalmente, na produção e fomento das desigualdades sociais, um dos fatores sociais determinantes do crescimento da criminalidade. Consciente disto e das conseqüências diversas provocadas pelo fortalecimento da ordem do capital, preocupado com os dias que virão, Thomas Piketty indaga:

Neste início de século XXI, certas desigualdades da riqueza que pensávamos ter desaparecido parecem estas prestes a voltar a seus picos históricos, ou até mesmo a ultrapassá-los, no contexto da nova economia global, portadora de imensas esperanças (o fim da pobreza) e de enormes desequilíbrios (tanto entre indivíduo como entre países). Será que podemos imaginar para o século XXI uma superação do capitalismo que seja ao mesmo tempo mais pacífica e mais duradoura, ou deveríamos apenas esperar pelas próximas crises ou pelas próximas guerras, verdadeiramente mundiais desta vez? Com base nas evoluções e nas experiências históricas que apresentamos aqui, quais instituições e políticas públicas permitiriam regular de maneira justa e eficaz o capitalismo patrimonial global no século que se inicia? (PIKETI, 2014, p. 459)

Muitos problemas são gerados e alimentados desta lógica perversa do capital. A política repressiva permanece vigente, ainda que disfarçada sob a forma de programas sociais. E diante de tais políticas repressivas o retrato social é único: superpopulação carcerária aliada ao caráter desumanizador e degradante das prisões. ${ }^{5}$

${ }^{5}$ Para mais informações sobre a superpopulação na Itália v. Barretta, 2014, p. 1 e ss. 
Seria neste ponto de evolução que pretendíamos chegar?

Uma simples análise da experiência estrangeira nos demonstra o contrário. Relativamente à superpopulação carcerária, oportuno recordar que a Corte Européia de Direitos Humanos condenou diversos países (Itália, Bélgica e Hungria) ao ressarcimento pela desobediência à disciplina contida no artigo 3 da Convenção Européia dos direitos humanos, a qual proíbe a tortura, as penas e os tratamentos desumanos e degradantes.

Especificamente no caso da Itália, a Corte condenou o país em Janeiro de 2013, através da famosa sentença Torreggiani, por ter mantido os recorrentes em espaços inferiores aos três metros quadrados estabelecidos como espaço mínimo necessário para não violar a dignidade humana e a disciplina do art. 3 da Convenção. A conduta omissiva do Estado italiano foi comparada ao crime de tortura, pois, além da insuficiência de espaço físico, concorriam outros graves problemas como falta de luz e ventilação, falta de condições higiênicas, etc. ${ }^{6}$

O encarceramento excessivo, visto como fator de agravamento da situação da criminalidade ainda é muito praticada pelos governos brasileiros. Atualmente, a quantidade de presos vem sendo chamada de "superpopulação carcerária" diante do altíssimo número de aprisionados no sistema penal. O próprio Ministério da Justiça admite o super encarceramento e os desdobramentos negativos decorrentes dele:

Basta registrar que partimos de noventa mil presos no início da década de noventa, e saltamos para mais de seiscentos mil presos, num intervalo de menos de 25 anos. Tal considerável incremento não se fez acompanhar de uma redução na incidência de crimes violentos, nem tampouco da sensação de segurança por parte da sociedade brasileira, o que em tese poderia justificar o enorme custo

\footnotetext{
${ }^{6}$ Considerando-se que o problema da superpopulação carcerária italiana consiste em um problema de caráter estrutural e sistêmico, a Corte adotou o mecanismo conhecido como "pilot judgment" para suspender todos os recursos contra o Estado até o fim do prazo estabelecido na sentença condenatória para a resolução do problema por parte da Itália, de modo a evitar futuras condenações. Assim o fazendo, além de indenizar os requerentes por violação ao art. 3 da Convenção, a Corte condenou a Itália a resolver o problema da superpopulação através de medidas capazes de garantir a aplicação da Convenção.
} 
social e financeiro do encarceramento. Pelo contrário, o cárcere tem reforçado mecanismos de reprodução de um ciclo vicioso de violência que, como padrão, envolve a vulnerabilidade, o crime, a prisão e a reincidência e, por vezes, serve de combustível para facções criminosas. (Dados do levantamento nacional de informações penitenciárias - INFOPEN de Dezembro de 2014, p. 07.

Disponível em: http://www.justica.gov.br/seus-direitos/politicapenal/infopen_dez14.pdf)

Segundo o Departamento penitenciário nacional, ao final de 2014 o Brasil ultrapassou a marca de 622 mil pessoas privadas de liberdade em estabelecimentos penais, chegando a uma taxa de mais de 300 presos para cada 100 mil habitantes, enquanto a taxa mundial de aprisionamento situa-se no patamar de 144 presos por $100 \mathrm{mil}$ habitantes. Com esse contingente, o país é a quarta nação com maior número absoluto de presos no mundo, atrás apenas de Estados Unidos, China e Rússia (INFOPEN, 2014, p. 06).

Tais dados, além de indicarem um progressivo aumento da população carcerária mundial, demonstram a dificuldade dos governos em adotar novas medidas e novas políticas públicas capazes de resolver a questão de modo definitivo.

José Paulo Netto, criticando a questão da segurança pública brasileira sob a ótica dos governos Lula (2003 a 2010) afirma que a discussão acerca da militarização da vida social não teria sido suficientemente abordada diante do "estado de guerra permanente e extermínio instalados nas principais metrópoles do país" e o problema do crescente encarceramento. (NETO, 2013, p. 42).

A falência do sistema prisional e a falta de investimento na prevenção da violência infelizmente são problemas que caracterizam a maior parte dos Estados e é exatamente por esta razão que se torna necessário maior investimento em projetos alternativos à prisão e em políticas públicas preventivas. Somente através do incremento de modos alternativos ao cárcere, do redimensionamento das penas, combinados com a construção e melhoria do atual parque penitenciário, com um grande investimento na justiça restaurativa e nos direitos sociais, será possível verificar uma razoável diminuição nos números acima citados, além da melhoria na situação de completa falta se segurança em que nos encontramos atualmente.

Convém ressaltar que o Estado italiano inspirado no 
programa brasileiro "bolsa família", criou o programa chamado SIA ${ }^{7}$ (apoio para a inclusão ativa) como forma de combater a crise, a pobreza e o desemprego no país. A proposta consiste em destinar uma quantia de até 400 euros por mês para as famílias de baixa renda em situação de vulnerabilidade (núcleos familiares com menores, deficientes ou gestantes). Aqueles que receberem o benefício deverão aderir ao projeto personalizado de inclusão no mercado de trabalho e no plano social, como forma alternativa de superar a própria condição de pobreza. Cabe mencionar que o governo italiano concederá o benefício somente a quem se empenhar na procura por emprego e se cumprir com os objetivos educacionais e sanitários (frequentar a escola e manter atualizado seu calendário de vacinas). Com esta iniciativa, espera-se que o investimento seja revertido em estímulo positivo que, além de reforçar a economia, auxilie na prevenção do fenômeno do desemprego e da delinquência, evitando, desta forma, o dano social e o custo do aparato criminal.

Avançando na temática específica das políticas públicas brasileiras, encontramos diversos programas importante e de grande relevo social. Dentre eles, temos o Programa Nacional de Segurança Pública com Cidadania (Pronasci) vigente desde 2007 e que se destina a articular ações de segurança pública para a prevenção, controle e repressão da criminalidade, estabelecendo políticas sociais e ações de proteção às vítimas (Artigo $2^{\circ}$ da Lei $\mathrm{n}^{\mathrm{o}} 11.530 / 07$, com redação dada pela Lei $\left.\mathrm{n}^{\mathrm{o}} 11.707 / 08\right){ }^{8}$

Designadamente quanto à prática de ações do PRONASCI, importante salientar o objetivo e o esforço em conjugar políticas públicas de segurança com políticas sociais já existentes haja vista que pretende atrelar esforços entre o Ministério Público, o poder judiciário, os governos (federal, estadual e municipal), a força nacional de segurança pública (que aos poucos cederá espaço para a polícia cidadã), as polícias civil e militar (ouvidorias de polícia bem como formação e aperfeiçoamento da polícia estadual) e a comunidade (por meio dos conselhos comunitários e do projeto mãe ouvidora).

$7 \quad$ Fonte: http://www.lavoro.gov.it/temi-e-priorita/poverta-ed-esclusionesociale/focus-on/Sostegno-per-inclusione-attiva-SIA/Pagine/default.aspx.

$8 \quad$ Disponível em: http://www.planalto.gov.br/ccivil_03/ato20072010/2007/Lei/L11530compilado.htm 
Dentre as diversas ações previstas na agenda do programa, destacamos: o programa de acolhimento ao jovem infrator ou em situação de risco criminal e à sua família; a formação cidadã, participação social e campanha do desarmamento; formação e estruturação do sistema penitenciário; modernização da gestão e aparelhamento das polícias e programa de Saúde para os Policiais (apoio psicológico e psiquiátrico).

Ainda no âmbito dos projetos governamentais, importante destacar a Lei $\mathrm{n}^{\circ}$ 12.681/12 que cria o SINESP - sistema nacional de informações de segurança pública, prisionais e sobre drogas. Segundo disposições expressas na legislação, o objetivo do sistema seria utilizar os dados compilados para ajudar na formulação de políticas de segurança pública, do sistema prisional e de execução penal, além de fortalecer o combate às drogas (artigos $1^{\circ}$ e $2^{\circ}$ da Lei 12.681/12).

Outrossim, a Secretaria Nacional de Segurança Pública SENASP - ligada ao Ministério da Justiça, se consolidou como um órgão central no planejamento e execução das ações de segurança pública em todo o Brasil (segundo informações obtidas junto ao Ministério da Justiça, relatório de atividades de 2003 até 2005) e o Instituto da Cidadania procura desenvolver propostas de políticas públicas para enfrentar os diversos tipos de violência do país, tendo como meta a redução da criminalidade. ${ }^{9}$

Tramita ainda na Câmara dos Deputados Federais o projeto de lei 3.734/2012 prevendo a criação do SUSP - sistema único de segurança pública - como integrante do PRONASCI. Tal sistema define questões de organização e funcionamento dos órgãos responsáveis pela segurança pública no país. O projeto atualmente aguarda parecer do relator na Comissão de Segurança Pública e Combate ao Crime Organizado (CSPCCO), após deverá ser apreciada pelas comissões de Finanças e Tributação; e de Constituição e Justiça e de Cidadania. ${ }^{10}$

Diversas são, portanto, as iniciativas vigentes na busca ao

\footnotetext{
${ }^{9}$ conforme informações obtidas junto ao Instituto da Cidadania relativamente ao projeto Segurança pública para o Brasil. Disponível em: http://www.observatoriodeseguranca.org/files/pnsp.pdf

10 informação obtida junto ao site da Câmara dos Deputados federais: http://www.camara.gov.br/proposicoesWeb/fichadetramitacao?idProposicao=542102
} 
combate à criminalidade. A despeito de todos os projetos aqui expostos e os demais existentes no país, a realidade acaba por demonstrar a ineficácia e ineficiência de tais institutos e propostas diante do alto crescimento dos índices de criminalidade e de violência. Sendo assim, uma grande reflexão surge na medida em que não se vislumbram, na prática, políticas públicas preventivas no tocante à segurança pública.

\section{CONCLUSÕES MEDIANTE ENFRENTAMENTO DO PROBLEMA}

Muitas das iniciativas anteriormente informadas são válidas, contudo é importante que se tenha presente a necessidade de efetivação prática de tais políticas preventivas, além do que estas precisam estar aliadas ao reforço do caráter não penal das políticas públicas de segurança. Em tese, as políticas existem e são representadas pelos programas, institutos e órgãos criados nos últimos anos (o próprio PRONASCI é um exemplo de política pública composta por uma série de diretivas orientadoras da questão da segurança pública). Contudo, na prática, não há efetiva redução da criminalidade ou estabilização da segurança pública.

Neste sentido, assevera André Leonardo Copetti Santos:

É necessário deixar claro que políticas criminais não implicam absolutamente em adoção de medidas restritas ao campo penal. Políticas sociais são políticas criminais muitíssimo mais eficientes que medidas penais. Nesse sentido, políticas criminais devem ser concebidas privilegiando a prevenção do delito através de políticas sociais positivas, afirmativas de minorias e de hipossuficientes economicamente, ao invés de se estruturarem, liminarmente, como políticas penais, consistentes em criminalizações, penalizações e outras alternativas, cunhadas dentro do universo de instrumentos instituídos pelo direito penal (SANTOS, 2010, p. 7).

A busca da eficiência para as políticas públicas passa, portanto, obrigatoriamente, pela origem do problema e deste modo as causas devem ser dissecadas através de análise profunda proporcionando assim a redução da sua incidência e, por via reflexa, a não ocorrência de condutas criminalizadas. Obviamente, se o 
motivo é extinto, não há razão para o cometimento do crime. Nesse sentido, Soares aduz que:

O crime torna-se causa do crime, pela mediação da economia e de outras esferas da vida social. Atuando-se sobre o crime, interrompese uma dinâmica autofágica, porque se afeta, positivamente, o conjunto dos fatores que funcionam como causas mediatas e imediatas do crime. Menos crime equivale a melhor economia, melhor qualidade de vida e, consequentemente, menos crime (SOARES, 2006, p. 95).

Assim, demonstra-se imprescindível que as políticas públicas tenham muito mais caráter social do que penal ou até mesmo penalizador (que impõe penas em excesso). A história corrobora com tal lógica a partir do momento em que demonstra a falência do atual sistema penal frente aos problemas como o super encarceramento, a especialização no mundo do crime dentro dos estabelecimentos prisionais, bem como pela busca de um sistema cada vez mais repressivo e encarcerador.

Como bem observa Arthur Trindade Costa:

Para discutir os limites e potencialidades das formas de intervenção do Estado em temas relacionados à segurança pública, é necessário distinguir alguns conceitos. As políticas públicas de segurança (policy) dizem respeito ao conjunto de ações e procedimentos que visam dar conta de determinada demanda ou problema através da alocação de bens e recursos públicos na área de segurança. As estratégias de policiamento (policing) referem-se às diferentes formas de aplicar os efetivos, recursos de poder e equipamentos policiais. Já uma Política Criminal (criminal policy) refere-se à articulação das ações e procedimentos adotados no interior do Sistema de Justiça Criminal com vista a responder a determinado problema ou situação. $\mathrm{Na}$ área de segurança pública, as políticas públicas não necessariamente se restringem às estratégias de policiamento e políticas criminais. Envolvem ações de outros atores governamentais e não-governamentais (COSTA, 2011, p. 98).

Independente da discussão de fundo acerca das políticas criminais, nitidamente há que se buscar a contribuição de atribuir uma dimensão social à problemática da delinqüência de forma a 
associá-la à reparação do bem-estar e da qualidade de vida.

A segurança, a par com a justiça e o bem-estar, continua a ser um dos fins últimos do Estado. A delinqüência em geral é vista como geradora de insegurança, donde é natural que se tomem medidas contra ela e, numa perspectiva de prevenção que se procurem identificar os fatores que contribuem para a sua aceleração. Os gestores da segurança pública almejam tomar iniciativas que sejam realizáveis com os recursos disponíveis e que possam alcançar sucesso num prazo razoável. Porém, o normal mesmo seria que procurassem respostas para conseguir resultados imediatos. Entendendo que necessitam de identificar o que fazer de concreto para em pouco tempo começar a resolver um problema, há quem defenda que podem de imediato atacar os sintomas daquilo que eventualmente sejam causas profundas e complexas da insegurança. O tratamento credível do conjunto das supostas causas da delinqüência e da insegurança é moroso e, por isso, não facilita a tomada de medidas a curto e a médio prazo. Se uma política de segurança baseada em medidas de prevenção e repressão da delinqüência, em termos clássicos, não substitui uma política social, então é possível que a análise da insegurança a partir das pequenas desordens ou incivilidades ponha em evidência alguns fatores sobre os quais se pode agir rapidamente, de modo a fazer baixar a delinqüência (COTTA, 2005, p. 12).

Paralelamente ao caráter repressivo da segurança, é possível observar um aspecto que promove políticas públicas visando reduzir os obstáculos existentes ao pleno acesso aos direitos garantidos pelo nosso ordenamento jurídico: trata-se de uma política que não se limita a proteger, reprimir ou contornar emergências passageiras, mas que se funda na promoção de direitos e na prevenção da violência (RUOTOLO, 2012, p. 18 e ss).

É natural que uma situação de emergência represente uma manifestação imediata de exigência de segurança, como ocorre, por exemplo, em períodos de guerra ou de terrorismo. Exatamente por este motivo, faz-se necessária uma intervenção sistemática a fim de diminuir o índice de delinquência para não suspender de modo injustificado o normal funcionamento da ordem constitucional, pois agir somente para melhorar os sintomas, sem investigar as causas, não produz resultados satisfatórios a longo prazo. 
Se imaginarmos o Direito como um rémedio (pharmakon), fica fácil entender o motivo pelo qual este, se não for dosado e utilizado de modo correto, pode revelar-se um veneno letal, e não um remédio de cura. O Direito, notadamente o Direito Penal, deve ser dosado proporcionalmente, pois o risco de se exagerar com punições e de estabelecer um estado policialesco é muito alto.

Exatamente por esta razão é necessário investir em modos alternativos ao Direito Penal para prevenir a criminalidade e a violência. Para a aplicação das políticas preventivas é indiscutível a necessidade de que estejam presentes certos subsídios como a participação popular da sociedade civil na forma de diálogo com os entes públicos. Irrefutavelmente estes elementos precisam ser trabalhados e aplicados para que haja efetividade quanto à prevenção. Entretanto, para que se compreenda de que modo a participação popular se dará, precisamos previamente absorver o caráter universalista que a segurança pública possui, ou seja, é atinente a todos seja manifestada sob a forma de dever do Estado, ${ }^{11}$ seja como direito fundamental e social do cidadão consagrado nos $\operatorname{artigos} 5^{\circ}$ e $6^{\circ}$ da Constituição Federal.

Assim, mais uma vez é possível identificar o liame entre políticas públicas e cidadania uma vez que engloba tanto a atuação estatal quanto à participação da sociedade civil. Para Potyara Pereira, não se consubstanciam direitos sociais sem políticas públicas que os concretizem e liberem indivíduos e grupos tanto da condição de necessidade quanto do estigma produzido por atendimentos sociais descomprometidos com a cidadania (PEREIRA, 2009, p. 99).

A segurança cidadã vem demonstrando ser o novo paradigma pautado na participação e atuação da sociedade civil em parceria com os governos em prol da segurança pública. Alguns programas e institutos vigentes na atualidade são os conselhos de segurança, o policiamento comunitário, as redes de vigilância, a conferência nacional de segurança pública e o conselho nacional de segurança pública. Cabe ressaltar que no Brasil as práticas de participação social tiveram origem nos anos 1980 durante o movimento de redemocratização, pós-ditadura militar.

Para além da violência e da criminalidade, as políticas

${ }^{11}$ Artigo 144 da Constituição da República federativa do Brasil de 1988. 
públicas de segurança devem conseqüentemente compactuar com uma reforma social, segundo Claudio Beato Filho:

A proposição de políticas públicas de segurança, no Brasil, consiste num movimento pendular, oscilando entre a reforma social e a dissuasão individual. (...). Consequentemente, propostas de controle da criminalidade passam inevitavelmente tanto por reformas sociais de profundidade como por reformas individuais voltadas a reeducar e ressocializar criminosos para o convívio em sociedade. A par das políticas convencionais de geração de emprego e combate à fome e à miséria, ações de cunho assistencialista visariam minimizar os efeitos mais imediatos da carência, além de incutir em jovens candidatos potenciais aos crime novos valores através da educação, da prática de esportes, do ensino profissionalizante e do aprendizado de artes e na convivência pacifica e harmoniosa com seus semelhantes (FILHO, 1999, p. 24).

A par de tudo que foi analisado e diante da realidade, especificamente brasileira, de criminalidade crescente, e para que ocorra a reconfiguração da segurança pública nacional é preciso ir além. Mais do que a inserção das organizações e institutos antes mencionados (SENASP, SUSP, SINESP, etc), faz-se necessária uma remodelação por meio de novas estratégias de atuação, revisão das atuais práticas policiais, uma nova agenda democrática de políticas públicas e mediante, primordialmente, ampla participação social sob pena de se agravar o problema da superpopulação carcerária ao ponto de desmoronar o terreno sólido capaz de sustentar os pilares do nosso ordenamento jurídico e penitenciário.

Resta inequívoca a necessidade de combate das causas que dão azo à criminalidade e isto implica dizer que as políticas públicas de segurança devem possuir caráter social, devem incidir sobre determinantes outras que não penais. Em razão do caráter multidisciplinar do problema, é preciso significativo investimento e atuação eficiente em saúde, educação, saneamento básico, como ponto de partida para qualquer possibilidade de mudança do atual paradigma estigmatizador. Se as causas já são publicamente e notoriamente conhecidas, devemos ir à fundo sobre elas.

Não se pode esquecer, entretanto, da problemática questão das drogas. Tratá-la exclusivamente como problema do sistema penal ou 
criminal é não combatê-la com efetividade. Droga é problema de saúde pública e como tal deverá ser tratada. Não basta que usuários e traficantes sejam encarcerados, é preciso ir além e exterminar com a oportunidade do fácil emprego propiciado pelo tráfico de entorpecentes. É preciso que o usuário tenha apoio através de redes de atendimento multidisciplinar que envolvam desde atendimento médico até psicológico e familiar.

O enfrentamento do problema, portanto, deverá ocorrer de forma multisetorial englobando a participação social; preconizando políticas sociais em detrimento da escolha apenas por políticas criminais; através do ataque às verdadeiras causas da criminalidade aliado, como já mencionado, aos diversos programas e institutos criados com o fim de monitorar os fatos, elaborar dados estatísticos concretos e que correspondam à realidade; bem como priorizar a ampla realização da cidadania dos cidadãos mediante efetivação dos direitos sociais.

\section{REFERÊNCIAS BIBLIOGRÁFICAS}

AZEVEDO, Rodrigo Ghiringhelli de; SANTOS, Mariana Chies Santiago. Políticas de Segurança Pública e Juventude: o caso do Rio Grande do Sul. O Público e o Privado (UECE), v. 21, Ceará, 2013. Disponível em: http://www.seer.uece.br/?journal=opublicoeoprivado\&page=article\&op=vie w\&path\%5B\%5D=691\&path\%5B\%5D=756

BARATTA, Alessandro. Diritto alla sicurezza o sicurezza dei diritti? In S. Anastasia, M. Palma (a cura di), La bilancia e la misura, Milano, 2001.

BARRETTA, Laura Uccello. Il sovraffollamento carcerario tra protezione dei diritti fondamentali e discrezionalità legislativa. Rivista AIC, Marzo, 2014.

BEATO FILHO, Cláudio Chaves. Dilemas do controle da criminalidade no Brasil. Revista Preleção, v. II, 2008. Disponível em: http://www.pm.es.gov.br/download/reistaprelecao/Revista_Prelecao_Edicao 04.pdf

. Políticas públicas de segurança e a questão policial. São Paulo em perspectiva, 13 (4), $1999 . \quad$ Disponível em: http://produtos.seade.gov.br/produtos/spp/v13n04/v13n04_02.pdf

BOURDIEU, Pierre. Sobre a televisão. Tradução Maria Lúcia Machado. 
Rio de Janeiro. Ed. Jorge Zahar, 1997.

COTTA, Francis Albert. A crise da modernidade e a insegurança social. Revista de humanidades MNEME, v. 07, $\mathrm{n}^{\circ}$ 14, 2005. Disponível em: http://www.periodicos.ufrn.br/mneme/issue/view/33

COSTA, Arthur Trindade M. É possível uma política criminal? A discricionariedade no sistema de justiça criminal do DF. Revista Sociedade e Estado, v. 26, n. 1, Brasília, 2011. Disponível em: http://periodicos.unb.br/index.php/estado/article/view/4081/3407

FILHO, José Vicente da Silva. Estratégias policiais para a redução da violência. Publicado pelo Instituto Fernand Braudel de Economia Mundial, São Paulo, $1998 . \quad$ Disponível em: http://pt.braudel.org.br/pesquisas/arquivos/downloads/estrategias-policiaispara-reducao-da-violencia.pdf

NETTO, José Paulo. Uma face contemporânea da barbárie. In: O social em perspectiva: políticas, trabalho, serviço social. Organizadoras Gilmasia M. Costa e Reivan Souza. Maceió, EDUFAL, 2013.

PEREIRA, Potyara Amazoneida Pereira. Abordagens teóricas sobre o Estado em sua relação com a sociedade e com a política social. Política Social: temas \& questões. 2. Ed. São Paulo, Ed. Cortez, 2009.

PIKETTY, Thomas. O capital no século XXI. Tradução de Monica Baumgarten de Bolle. Rio de Janeiro, Ed. Intrínseca, 2014.

RAMOS, Silvia. Violência, crime e mídia. In: Crime, polícia e justiça no Brasil. Organização Renato Sérgio de Lima, José Luiz Ratton e Rodrigo Ghiringhelli de Azevedo. São Paulo, Ed. Contexto, 2014.

RUOTOLO, Marco. Dignità e carcere. Napoli, Editoriale Scientifica, 2011. . Sicurezza, dignità e lotta alla povertà. Napoli, Editoriale Scientifica, 2012.

SANTOS, André Leonardo Copetti. Políticas públicas e tratamento da criminalidade numa sociedade democrática. Revista de Direito da UNISC, Santa Cruz do Sul, nº 33, 2010.

SCHABBACH, Letícia Maria. Políticas públicas de segurança, relações intergovernamentais e prevenção da violência. $8^{\circ}$ ENCONTRO DA ASSOCIAÇÃO BRASILEIRA DE CIÊNCIA POLÍTICA - ABCP, Gramado/RS, 2012. Disponível em: http://www.cienciapolitica.org.br/wpcontent/uploads/2014/04/6_7_2012_12_45_33.pdf

SILVA, Jorge da. Direitos humanos versus lei e ordem: desconstruindo paradigmas de políticas públicas no Rio de Janeiro. Trabalho apresentado 
no VIII Congresso Luso-afro-brasileiro de Ciências Sociais, Coimbra/Portugal, 2004.2 Disponível em: http://www.ces.uc.pt/lab2004/inscricao/pdfs/painel56/JorgedaSilva.pdf

SOARES, Luiz Eduardo. Segurança pública: presente e futuro. Revista de estudos avançados v. 20, v. 56, São Paulo, 2006. Disponível em: http://www.scielo.br/pdf/ea/v20n56/28629.pdf 